\title{
The Rational Thinking of Promoting Ecological Civilization Construction in the Universities
}

\author{
Naizhu Huang ${ }^{1,}$, Jiaming Zhong ${ }^{1, b}$ and Yuan Xiao ${ }^{1, c^{*}}$ \\ Xiangnan University, Chenzhou, Hunan, China, 423000 \\ ahuangnzh@163.com,bjmzhongcn@163.com, ‘yuanyuan_8603@qq.com \\ *The corresponding author
}

Keywords: Universities; Ecological environment; Ecological civilization.

\begin{abstract}
In order to implement the Party's basic spirit of ecological civilization construction in the eighteenth congress, the universities which its core tasks is personnel training should actively promote the sustainable development education in practicing ecological civilization construction. The sustainable development education requires universities actively develop green school construction, and actively advocate ecological way of life, and contribute to achieve the great goal of the beautiful China.
\end{abstract}

\section{高等学校推进生态文明建设的理性思考}

\author{
黄乃祝 $^{1, a}$, 钟嘉鸣 ${ }^{1, b}$, 肖媛 ${ }^{1, c *}$ \\ 湘南学院，湖南 椰州 423000 \\ ahuangnzh@163.com, bjmzhongcn@163.com, cyuanyuan_8603@qq.com \\ *通讯作者
}

摘要：为了贯彻落实党的十八大关于生态文明建设基本精神，作为人才培养核心任务的高等 学校践行生态文明建设应积极推进可持续发展教育。可持续发展教育要求高等学校积极开展 绿色学校建设，积极倡导生态型生活方式，为实现“美丽中国”宏伟目标贡献力量。

关键词：高等学校; 生态环境; 生态文明

\section{1. 引言}

党的十八大把生态文明建设放在突出地位，纳入中国特色社会主义事业五位一体总体布局之 中，明确提出大力推进生态文明建设，努力建设美丽中国，实现中华民族可持续发展的伟大 目标。当今世界，人类因过分追求更加舒适而又美好的生活，导致地球遭受着有组织、大规 模、不间断地伤害而日趋病态: 工业污染严重、土壤沙漠化、雨林和湿地减少、物种加速灭 绝、臭氧层遭难导致全球气候变暖。面对环境的持续恶化，地球用以修复、更新和再平衡的 生态能力严重不足, 如此下去, 人类在不确定的未来必将面临环境灾难。为了避免不确定环 境灾难，人类急需检讨现有发展观念，即被学者们称为发展主义一一一种表示狭险化发展意 识形态的观念 [1]，因为这种观念导致发展过程中的病态特征：整个区域被高速发展的幻象所 迷惑，从而沉浸于国内生产总值的提升或物质财富的聚集，进而造成了对环境、生态、道德、 精神等问题的忽视。联合国自 1972 年在瑞典召开人类环境会议至今，人类为拯救地球做出了 积极努力，各国政府相继制定保护生物多样性、治理污染、节能减排等法律。然而，随着社 会发展，人类逐渐认识到，单纯强调环境利益而试图抑制人类活动是不现实的，发展永远是 人类生活的主题。尤其是通过发展可以消除贫困、减少地区差异、提高人民生活水平，这些 
都有利于世界和平与稳定。所以，人们把对环境问题的片面关注逐渐转移到环境与发展间的 协调上, 积极倡导可持续发展理念, 即“既满足当代人的需要, 又不对后代人满足其需要的能 力构成危害的发展” [2]。集培养人才、传播知识、专研学术、教化社会等多种职能于一体的高 等学校在推进生态文明建设中应积极实践可持续发展教育, 为建设“美丽中国”做出表率。

\section{2. 生态文明建设召唤可持续发展教育}

深入理解和把握生态文明内涵是积极推进生态文明建设的重要前提。生态是自然界的存在状 态, 文明是人类社会的进步状态, 生态文明则是人类文明中反映人类进步与自然存在和谐程 度的状态。生态文明的本质要求就是要尊重自然、顺应自然和保护自然。尊重自然就是要从 内心深处承认人是自然之子, 而非自然之主宰, 对自然怀有敬畏之心、感恩之意、报恩之情, 绝不能有凌驾自然之上的狂妄错觉; 顺应自然就是要使人类活动符合而不是违背自然界客观 规律, 当然顺应自然不是任由自然驱使, 停止发展甚至重返原始状态, 而是在按客观规律办 事前提下, 充分发挥人的能动性和创造性, 科学合理地开发利用自然; 保护自然就是要求人 类在向自然界获取生存和发展之需同时, 要呵护自然、回报自然, 把人类活动控制在自然能 够承载的限度内, 给自然留下恢复元气、休养生息、资源再生的时间, 实现人类对自然获取 和给予的平衡, 防止出现生态赤字和人为造成的不可逆的生态灾难。建设生态文明必须按照 科学发展观要求, 走出一条低投入、低消耗、少排放、高产出、能循环、可持续的新型发展 道路, 形成节约资源和保护环境的空间格局、产业结构、生产方式和生活方式。生态文明建 设离不开可持续发展教育, 联合国教科文组织主任前总干事马约尔就认为: “教育、科学和政 治意识是人类与环境和谐共处的三大支柱”[3]。什么是可持续发展教育? 1987 年联合国大会 上，世界环境与发展委员会在《我们共同的未来》报告中首提可持续发展概念；1992 年里约 热内卢联合国环境与发展大会正式采纳这一概念, 并签署《21 世纪议程》, 提出具体实施可 持续发展战略的行动依据、目标、活动和实施手段, 成为世界各国实施可持续发展战略的行 动指南和准则; 2002 年, 联合国在南非约翰内斯堡举行全球瞩目的世界可持续发展峰会, 与 会各国首脑一致通过将 2005-2014 年确定为“可持续发展教育十年”，强调教育是实现可持续 发展的不可缺少的组成部分。可持续发展教育就是一种全球教育发展战略, 通过实施可持续 发展教育促使学生认识到生态系统之间的相互依存关系, 认识到人类自身的活动与决策在现 在和将来对资源、对当地社区、对全球以及整个环境所造成的影响, 从而最终使学生形成保 护环境的意识、价值观以及可持续发展的生活观, 掌握相应的知识与技能, 并能有效的参与 到当地、国家及全球的可持续发展战略中去。

\section{3. 高等学校积极践行可持续发展教育}

党的十八大把生态文明建设融入经济建设、政治建设、文化建设、社会建设之中, 提出加快 建设资源节约型、环境友好型社会, 努力建设“美丽中国”宏伟目标。人才培养作为核心任务 的高等学校积极践行生态文明建设首要任务就是如何实施可持续发展教育, 通过可持续发展 教育, 使学校成为环境优雅、资源节约、生活舒适的绿色学校, 使师生养成保护环境的意识、 绿色消费理念以及可持续发展的生活方式等。

3.1. 高等学校积极推进绿色学校建设

绿色是光谱中介于蓝和黄之间的那种青中带黄颜色。自然界的绿色是生命生生不息、万物生 态和谐的颜色; 是生命的象征、青春的标志, 具有激发人奋发向上、积极进取的情绪。绿色 蕴藏着生机和活力, 昭示着温馨和亲情, 象征着清幽与和平, 充满着健美和希望。绿色的灵 魂是绿色植物, 绿色植物的细胞叶绿体内叶绿素能捕捉太阳光能将二氧化碳和水等无机物合 成葡萄糖等有机物, 同时释放氧气, 这一过程就是光合作用, 光合作用是生物界获得能量、 
食物以及氧气、维持地球生命活动的根本途径, 它吸收二氧化碳释放氧气, 对于维护良好的 生态环境有极其重要的作用。据测定每公顷绿地每天能吸收 $900 \mathrm{~kg}$ 二氧化碳, 生产 $600 \mathrm{~kg}$ 的 氧气。一个成年人, 每天呼出 $0.9 \mathrm{~kg}$ 二氧化碳, 消耗 $0.75 \mathrm{~kg}$ 的氧气, 即每个人约需 10 平方米 的绿地, 才能除掉排出的二氧化碳, 按联合国环境组织研究, 人均绿地面积达 60 平方米的城 市才能称为适宜人居住的城市[4]。

绿色学校是指实施绿色教育、拥有绿色观念的学校, 绿色学校是一个充满活力与希望的学校。 绿色学校建设应以可持续发展思想为指导, 不断完善自我管理、改进教育手段、降低教育投 人、提高办学效率和效益。绿色学校创建, 绝不仅指种花、种草、栽树, 甚至也不是指开设 一门课程或改变课程计划, 它关系到节省资源、减少污染、实施开放管理、强调分享观念、 营造和谐人际环境和尊重多样化的文化和价值取向等更重要的方面, 建设绿色学校意味着对 我国现有的高校教育、教学体系进行系统变革。1982 年绿色大学在意大利成立, 设置有生态 平衡、替代能源、自然医疗、废料处理和环境保护等课程，该校毕业生颇受欢迎。1991 年清 华大学开始筹建绿色大学, 1998 年推出绿色大学计划, 倡导在绿色大学建设中开展“绿色教 育”、“绿色科技”和“绿色校园”三绿建设工程; 1999 年 5 月, “大学绿色教育国际学术研究会” 在清华大学召开, 会上 20 多所国内知名大学发表了《长城宣言: 中国大学绿色教育计划行动 纲要》, 标志着大学绿色教育发展进人新阶段。

3.1 .1 高等学校实施绿色教育

绿色教育就是全方位的生态意识、生物多样性保护意识、环境意识和可持续发展意识的教育, 通过教育使全体学生均成为一个有责任的地球公民。

绿色教育强调高校各项活动开展首先要节约资源。学校是一个污染源, 学校设施及运营过程 所消耗的能源和排放的污染物的综合折算成温室气体的排放量, 在全国范围来看数量相当庞 大, 因此, 学校要自觉降低能源消费, 采取措施充分利用和节约自然资源未改善学校环境, 如建立雨水收集设施, 把雨水积蓄起来浇花浇树, 节约自来水, 有条件的学校还可考虑建立 校内水循环系统, 使污水经过处理循环再利用。学校要提倡低碳办公, 少发纸质文书、多发 电子文稿, 室内空调温度设置夏季不低于 $26^{\circ} \mathrm{C}$, 冬季不高于 $20^{\circ} \mathrm{C}$, 人人树立起节约的意识、 养成节约的习惯、开展节约的活动。学校校舍尽量使用对环境良好的建筑材料, 减少能源的 使用, 减少对空气的污染。学校垃圾减量化和无害化处理, 实施生物垃圾堆肥和其他垃圾的 分类。对教师环境教育能力进行培训, 使之能够带领学生研究太阳能、风能及其他清洁能源 的利用等。

绿色教育要求高校要在保护生物多样性上做出典范。一所高校如果绿树成荫, 鸟语花香, 人 与动植物和谐相处, 那是很迷人的。目前, 生物多样性面临危机, 不仅原生自然中野生动物 正在迅速面临灭绝, 人们身边的野生动物也面临生存危机。为了确保生物多样性首先确保各 地区野生动物生息与生育的土地不被破坏, 绿色高校不仅要考虑教育设施的特性, 适当削减 环境负荷, 还要将学校生态园建设作为保全本地生物和生态系统的教育基地纳入视野。欧洲 生态学校的环境建设过程中特别重视用纯粹自然对学生施加影响: 校园建设体现生态友好理 念, 树立垂直绿化的概念, 把校园绿化延伸到屋顶与墙壁; 对泥土的谦卑态度表现为不追求 学校操场 $100 \%$ 硬覆盖, 而要留出田园或花园用地, 好让学生开展实践活动, 有条件的学校还 在校园里保留或建设水塘, 好让学生从中了解实地生态系统的生物多样性。在校园里保留自 然生态, 使学生更多的亲近自然, 使学校本身成为一个亲近自然的典范。

3.1 .2 高等学校实施绿色校园建设

绿色校园建设就是要让森林走进学校, 让学校拥抱森林, 做到校在林中、路在绿中、楼在园 中、山水相融。校园绿化要以植物造景为主, 多种植各类乔灌木和地被植物, 利用不同冠型、 不同色彩的乔灌木和地被植物搭配成错落有序的多层次和多色彩的植物景观, 形成春花、夏 荫、秋色和冬绿的四季景物, 以最大限度发挥绿地的生态效益, 形成优雅宜人的育人环境。 
校园绿化要体现文化内涵, 园林管理者要认真研究园林艺术, 结合本校特点精心设计, 使得 校园绿化既要展现优美的校园景观, 又要创造优美的校园文化。校园绿化过程中种植树木还 要考虑树木对人体健康的影响。一般来说, 绿色植物除了通过光合作用吸收二氧化碳释放氧 气外, 还能吸收大气中二氧化硫等有害气体, 具有挡风、除尘、杀菌、降低噪音、调节气温 和保持空气湿度等诸多功能。如杨、垂柳、榆和丁香等具有很强的吸收有害气体二氧化硫的 能力; 银桦、桑树、柳等对大气中的氮氧化物净化能力很强; 仙人掌、文竹、常青藤、秋海 棠等能释放芳香化合物杀死大气中的病毒和细菌; 夜来香、锦紫苏、驱蚊草等释放气味具有 驱蚊和除蝇作用; 丁香、茉莉可使人放松, 有利于睡眠; 玫瑰、紫罗兰可调节人的神经系统, 可使人精神愉快和发奋工作。以上这些植物可大量种植, 只是需要注意的是释放香味植物不 宜太多, 因为香味太浓会引起副作用, 如丁香久闻会引起烦闷气喘, 影响记忆力; 夜来香夜 间排出废气使高血压、心脏病患者感到郁闷; 郁金香含毒碱, 连续接触两个小时以上会头昏; 含差草有差碱, 经常接触引起毛发脱落。有些植物毒性较强, 应尽量少种植, 如夹竹桃全株 有毒, 含有多种强心式, 中毒后会恶心呕吐、腹泻, 可致命; 水仙花鳞茎有毒, 含有石蒜碱 等, 中毒后会呕吐、腹痛; 一品红其白色浮汁有毒, 人体接触后能引起皮肤红肿, 误食后会 呕吐、腹痛; 万年青内含草酸和天门冬毒等, 如果误食可致口腔、咽喉、食 道、胃肠粘膜等 灼伤, 甚至损害声带。有些植物据说可促癌, 至今虽没有确切报道, 但还是应避免, 如石粟、 变叶木、细叶变叶木、蜂腰榕、石山巴豆、毛果巴豆、巴豆、麒麟冠、猫眼草、泽漆、甘遂、 续随子、高山积雪、铁海棠、千根草、红背桂花、鸡尾木、多裂麻疯树、红雀珊瑚、山乌柏、 乌柏、圆叶乌柏、油桐、木油桐、火殊勒、芫花、结香、狼毒、黄芫花、了哥王、土沈香、 细轴芫花、苏木、广金钱草、红芽大戟、猪殊殊、黄毛豆付柴等, 其中铁海棠、变叶木、乌 柏、红背桂花、油桐、金果榄等一些市民家中及公园里常见的观赏性花木均含有促癌物质, 学生需科学观赏。

3.2. 高等学校积极倡导生态型生活方式

生活方式就是指在一定的社会条件制约下, 在一定的价值观指导下, 所形成的满足自身需要 的生活活动形式和行为特征的总和。从古至今, 人类社会生活方式的变迁可分为四个阶段: 远古社会生活方式、农业社会生活方式、工业社会生活方式、生态型生活方式。目前, 世界 上以美国为首的绝大多数资本主义国家追求的是以“高消费、高浪费”为主要特征的工业社会 生活方式, 这种生活方式隐含着 “消费越多越体面”观念, 不仅鼓励人们以贪得无厌的态度去 消费资源、能源和商品, 而且刺激人们尽可能多地把它们消耗和浪费掉。正是这样一种生活 方式把人类自己推向危境甚至绝境, 因为这种生活方式不是为求生存、求温饱的奋斗实践, 而是一种多余的贪婪和占有欲的追求。“我们再也不能把地球这颗小行星当作一个无穷无尽的 舞台, 当作可以为人类提供各种资源, 对人的每一种需要都慷慨给予而没有极限的母亲了”, 20世纪70年代以来，在发达国家出现的环保主义者倡导“自愿简单化的”、“回归自然的”生态 型生活方式, 已得到越来越多人的赞同和响应。何谓生态型生活方式? 生态型生活方式就是 改变以往那种高消费、高浪费的生活态度, 主张节约型的、更讲究科学合理的、更注重消费 质量的生活消费观。生态生活方式是一种绿化的或生态化的消费模式, 这种消费模式既符合 物质生产的发展水平, 又符合生态生产的发展水平, 既能满足人的消费需求, 又不对生态环 境造成危害。生态型生活方式表现在物质生活方面, 抛弃“多多益善”消费观念, 提倡以满足 基本需要为主, 节约资源, 尽力减少直至消除个人对环境的破坏。随着科技进步, 发展可再 生洁净能源, 减少交通工具使用, 研制新型的、没有污染或污染很小的交通工具; 在精神生 活方面, 人们从过去那种过分追求物质层面的东西, 转为对科学、艺术、信仰等精神层面东 西的追求, 在减少物质欲望和物质追求的情况下, 增加闲暇时间, 建立更加融洽的家庭关系、 人际关系和社会关系, 以健全的心理、信仰、审美和道德追求达到丰富的精神生活的满足, 这是人与自然和谐和进步的生活方式。 
高等学校在实施可持续发展教育过程中, 要积极宣传和努力践行生态型生活方式。高校应号 召全体师生在日常饮食、公务招待、各种宴会中提倡素食理念、绿色消费、“光盘”运动; 高 校要教育引导全体师生常怀自然之思: 人类不是自然的主宰, 人类在广䘚宇宙中不仅是尘埃, 简直是虚无; 自然不仅是人类的挚友、师长，更是人类的恋人，它给予的恩典和慈爱不仅让 人类身心愉快, 更让人类认识生命的价值与真谛; 古人将自然作为图腾崇拜的对象; 道家认 为自然是超越物质生活的灵性意识; 理学家觉得可借助自然悟道, 追求人与自然的和谐; 禅 宗强调人只有接近大自然才能恢复本源状态; 圣哲先贤如陶渊明、梭罗、卢梭等自然浪漫主 义者的朴素田园生活情怀、那“按照自然而生活就是按照德性而生活”的“天人合一”境界、那 “一日千年、千年一日的肉体永生”神仙境界不正是生态型生活方式的缩影吗？高校要教育引 导全体师生崇节俭、戒贪欲: “俭，德之共也；侈，恶之大也”、“俭节则昌，淫佚则亡”。崇 尚艰苦朴素、清心寡欲生活不仅有益身心健康, 还能确保高尚的志向和远大理想。先哲诸葛 亮“非淡泊无以明志，非宁静无以致远”、欧阳修“忧劳可以兴国，逸豫可以亡身”、王应麟所 撰《三字经》“人遗子, 金满嬴, 我教子, 唯一经”等典故难道不值得现代人学习? 我国现代 著名画家马绰的“行走中国, 宣传素食”环保马拉松活动[5]倡导人们为了保护环境, 请少吃肉 多吃素食, 这不仅有益身体健康, 而且有益人类可持续发展, 这种大爱、大义行动不就是在 倡导生态型生活方式吗?

\section{4. 致谢}

本研究得到2015年湖南省普通高等学校教学改革研究立项项目《地方高校转型发展的理论与 实践研究——以湘南学院为例》(湘教通 [2015]291号); 湖南省教育科学“十二五”规划2014 年立项课题《教育综合改革背景下的地方高校多元治理模式研究》 (XJK014BGD076) 的支持。

\section{参考文献}

[1] 许宝强. 前言: 发展、知识、权力 $[\mathrm{M}] / /$ 许宝强, 汪晖. 发展的幻象. 北京: 中央编译出版 社, $2001:$ 前 1 .

[2] 世界环境与发展委员会. 王之佳、柯金良译. 我们共同的未来 [M]. 长春: 吉林人民出版 社. $1997: 52$.

[3] A. J. S Rayl著. 谢敏华译. 可持续发展教育 [M]. 世界自然保护联盟通讯. 1999:8-9.

[4] 苗以农, 朱长甫等. 绿色生命和绿色教育 $[\mathrm{J}]$. 生物学通报. 2002（9），13.

[5] 郑翔. 行走中国宣传素食，终点是台湾 [N]. 椰州新报，2013-5-14,03版.

\section{Acknowledgement}

This study is supported by Hunan Education Science "the 12th Five-Year Plan" 2014 Approval Project: Multivariate Management Model Study of Local Colleges and Universities under Education Comprehensive Reform (XJK014BGD076), 2015 Hunan ordinary colleges and universities education innovation research project "The theory and practice research of transitional development in local colleges and universities--take Xiangnan University as example" (Xiang Jiao Tong [2015]291)

\section{References}

[1] Xu Baoqiang. Preface: Development, knowledge and power [M]//Xu Baoqiang, Wang Hui. The vision of development. Beijing: Central Compilation press, 2001: top 1. 
[2] World Commission on environment and development. Wang Zhijia, Ke Jinliang translation. Our common future [M].Changchun: Jilin people's publishing press, 1997:52.

[3] A.J.S Rayl. Xie Minhua translation. Sustainable development education [M]. Communications of the World Conservation Union. 1999:8-9.

[4] Miao YiNong, Zhu Changfu et al. Green life and green education [J].Biological bulletin.2002 (9), 13.

[5] Zheng Xiang. Walking China to promote vegetarian, the end is Taiwan [N]. Chenzhou daily news, 2013-5-14, 03.

[6] Wang QJ, Wu JT. "Thoughts on Integrating Innovation and Entrepreneurship Education into the Whole Process of Talent Training", Advances in Computer Science Research, vol.25, pp.149-152, 2015. 